\title{
Tissue Destruction Caused by Entamoeba histolytica Parasite: Cell Death, Inflammation, Invasion, and the Gut Microbiome
}

\author{
Swagata Ghosh ${ }^{1} \cdot$ Jay Padalia $^{1} \cdot$ Shannon Moonah ${ }^{1,2}$
}

Published online: 21 January 2019

(C) The Author(s) 2019

\begin{abstract}
Purpose of Review Entamoeba histolytica is a protozoan parasite that causes amebiasis, which remains a significant cause of morbidity and mortality worldwide. E. histolytica causes tissue destruction which leads to clinical disease. This review outlines some of the recent advances that have furthered our understanding of the processes that lead to the tissue damage caused by E. histolytica.

Recent Findings Recent studies have identified new mechanisms involved in E. histolytica-induced tissue damage. These include (i) new form of contact-dependent killing called trogocytosis; (ii) parasite-produced cytokine, macrophage migration inhibitory factor, that contributes to inflammation; (iii) exploitation of host immune response to promote invasion; and (iv) the contribution of the gut microbiome to clinical disease.

Summary Targeting these mechanisms that result in tissue injury should be a focus of future research for the development of improved preventive and therapeutic strategies for amebiasis.
\end{abstract}

Keywords Amebiasis · Trogocytosis $\cdot$ Microbiome $\cdot$ Invasion $\cdot$ E. histolytica macrophage migration inhibitory factor

\section{Introduction}

Entamoeba histolytica is a pathogenic protozoan parasite that causes amebiasis in humans. E. histolytica infection can be asymptomatic or lead to severe disease with amebic colitis and amebic liver abscess. Amebiasis remains a significant cause of morbidity and mortality worldwide. E. histolytica infection is estimated to kill more than 55,000 people each year [1••]. Globally, diarrheal disease is the third leading cause of death in children under 5 years of age with amebic colitis being a leading cause of severe diarrhea in low-income countries $[1 \bullet \bullet$. Fulminant amebic colitis is an uncommon but lifethreatening complication, and on average, more than $50 \%$ with severe colitis die [2•]. E. histolytica infection is also a

This article is part of the Topical Collection on Parasitology

Shannon Moonah

sm5fe@virginia.edu

1 Department of Medicine, University of Virginia School of Medicine, Charlottesville, VA, USA

2 Division of Infectious Diseases, Department of Medicine, University of Virginia Health System, 345 Crispell Drive, MR-6 1st floor, Room 1709, Charlottesville, VA 22908, USA concern among returning travelers with infectious gastrointestinal disease, with an incidence of 14/1000 unwell travelers [3]. Nitroimidazoles are the only treatment for invasive amebiasis. Nitroimidazoles are toxic drugs, and resistance to them has developed in other anaerobic protists [ $[\bullet \bullet$. Also, efforts to prevent disease are complicated by the lack of a vaccine. Therefore, it is crucial to understand amebiasis pathogenesis as a way forward to better approaches for treatment and prevention (Table 1).

E. histolytica parasite exists in two forms, a cyst stage and a trophozoite stage. The life cycle of E. histolytica begins with the ingestion of the infectious cyst from fecally contaminated food or water or through oral-anal sexual practices. The cysts pass through the stomach and small intestine where they excyst and form invasive trophozoites in the lumen of the intestine. Trophozoites can penetrate the mucus layer of the large intestine. Disease outcomes, namely colitis and liver abscess, are associated with vast tissue damage. For example, amebic colitis is characterized by colonic ulcers with invasion of parasites into the lamina propria and an infiltration of inflammatory cells such as neutrophils [4] (Fig. 1).

Tissue damage caused by E. histolytica is a result of three main events: host cell death, inflammation, and parasite 


\section{Table 1 Key points}

E. histolytica-induced tissue damage is a result of 3 main events: host cell death, destructive inflammatory response, and parasite invasion.

Amebic trogocytosis is a recently discovered mechanism for host cell killing.

A specific parasite-encoded cytokine, E. histolytica macrophage migration inhibitory factor (EhMIF), mediates inflammation during amebiasis.

E. histolytica exploits the host inflammatory response to promote tissue invasion.

Gut microbiome influences the clinical outcomes of E.histolytica infection.

invasion. This report reviews recent literature expanding our knowledge of the pathogenesis of amebiasis (Fig. 2).

\section{Cell Death}

E. histolytica has the remarkable ability of direct killing of host cells. The mechanism of cell killing by E. histolytica has been the subject of intensive investigation for several decades. Adhesion to host cells is a critical factor for the killing activity of E. histolytica. Gal/GalNAC lectin is the major parasite adherence molecule that is required for the contactdependent cell killing by E. histolytica. The process of cytotoxicity primarily involves programmed cell death (apoptosis) as demonstrated by TUNEL and annexin V staining showing DNA fragmentation and membrane blebbing. Several independent studies have shown that caspase- 3 activation leads to the induction of programmed cell death [5], though the pathway that mediates this response is not fully understood. One theory is that parasite contact causes elevation of intracellular calcium in host cells, which ultimately leads to global protein tyrosine dephosphorylation and activation of caspase-3 [6].

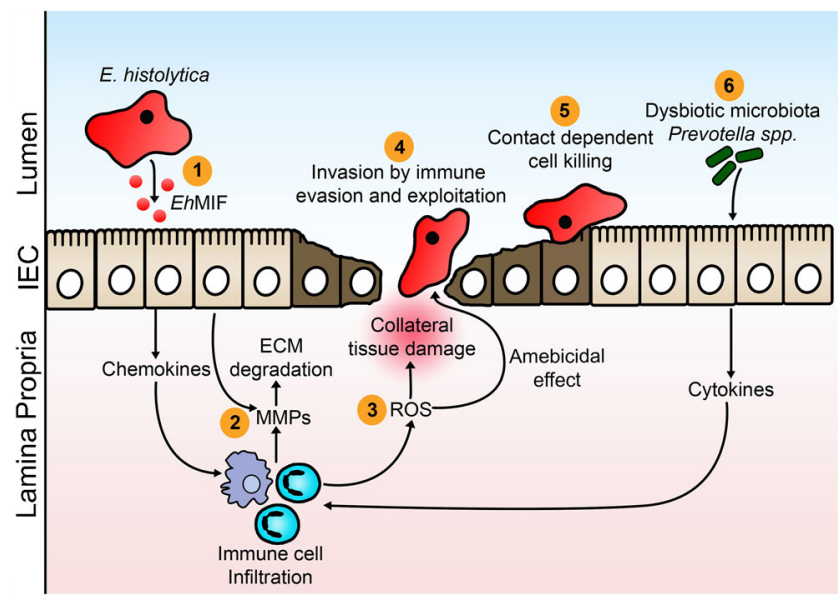

Fig. 2 Pathogenesis of intestinal amebiasis. 1. Secreted E. histolytica macrophage migration inhibitory factor $(E h \mathrm{MIF})$ promotes mucosal inflammation. 2. E. histolytica-induced inflammation results in increased production in matrix metalloproteinases (MMPs) which break down extracellular matrix (ECM) in the gut to promote cell migration. 3 . Infiltrating inflammatory cells generate oxygen free radicals (ROS) which are capable of killing parasites. Oxygen free radicals are also responsible for collateral tissue damage during the inflammatory period. 4 . $E$. histolytica invades the intestinal mucosa by evading and exploiting the host immune system. 5. Contact-dependent cell killing by E. histolytica. 6. Elevated levels of P. copri increases the risk of colitis

What are the parasite cytotoxic effector molecules that trigger host cell death? It has been proposed that E. histolytica secretes proteins, such as amoebapores, that have cytotoxic effects on human cells. However, this theory is challenged by the failure of E. histolytica-secreted fractions to kill host cells.

E. histolytica is also capable of ingesting host cells by a process of phagocytosis. Phagocytosis is believed to play a crucial role in amebic pathogenesis as well as nutrient uptake [7]. In vitro studies have shown that $E$. histolytica is capable of ingesting a variety of host cells. However, E. histolytica trophozoites obtained from clinical samples, including colonic ulcer biopsy, mainly consist of one cell type which is ingested red blood cells $[1 \bullet \bullet]$.
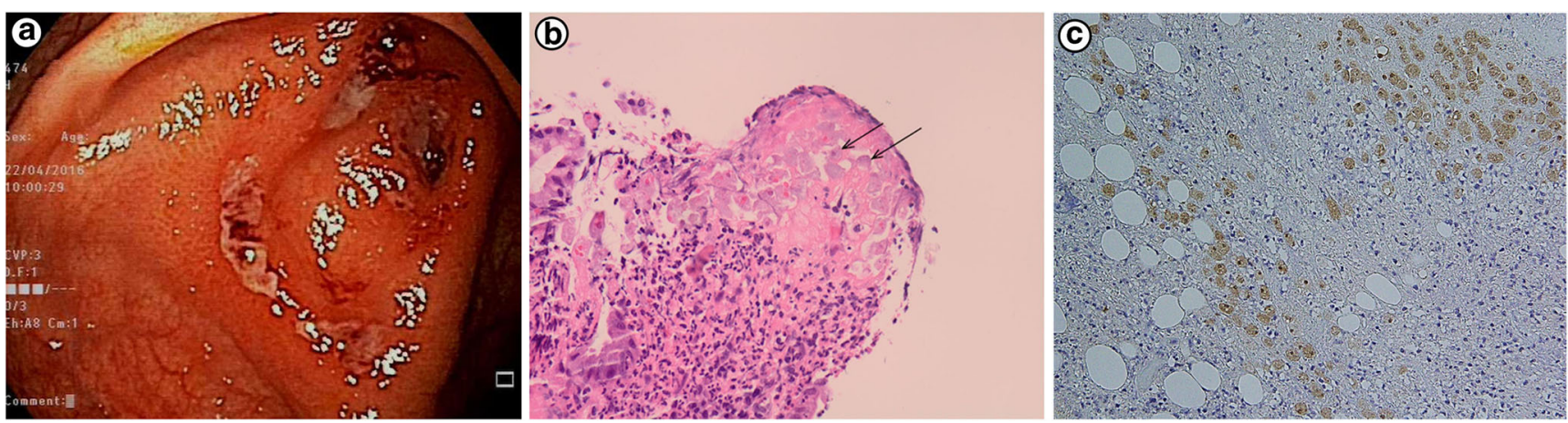

Fig. 1 Patient with amebic colitis. a Intestinal ulcers due to E. histolyica. b E. histolyica within the lamina propria (arrows) surrounded by inflammatory infiltrate of neutrophils. c Invasion of intestinal mucosa by amebic trophozoites. Immunohistochemical staining of trophozoites (brown) using specific anti-Entamoeba histolytica macrophage migration inhibitory factor antibodies. Panels $(\mathrm{a}, \mathrm{b})$ are reproduced from $[4]$ and $(\mathrm{C})$ from $[1 \bullet \bullet]$ with permission 
More recently, real-time observation of cell killing by $E$. histolytica revealed that the parasite, prior to cell death, ingests distinct "bites" of live host cells by a process called "trogocytosis" [8••]. This leads to intracellular $\mathrm{Ca}^{2+}$ elevation and loss of membrane integrity in the host cells, ultimately causing cell death. Parasites were found to detach from the dead cells. Also, live host cells were preferentially ingested by amebic trogocytosis while pre-killed cells were taken up by phagocytosis. Although the molecular mechanism behind trogocytosis is not well understood, it was shown that the overlapping signaling pathways involving EhC2PK and PI3K, at least partially, regulate both phagocytic and trogocytic processes. Though there are several pathways common to both processes, differences likely exist. Researchers recently attempted to understand how trogocytosis was mechanistically distinct from phagocytosis. AGC family kinase 1 was found to be specifically involved in trogocytosis of live human cells and did not participate in phagocytosis of dead cells [9].

Biological processes equivalent of E. histolytica trogocytosis were previously identified in other human pathogens such as Naegleria fowleri. However, parasites like $N$. fowleri use a specialized cytoplasmic extension called "amoebostome" or "food-cup" for host cell attachment and ingestion [10]. Structures homologous to Naegleria "foodcup" have not been found in E. histolytica, suggesting variations in this apparently similar process between organisms.

It appears that not all human epithelial cells are vulnerable to E. histolytica trogocytosis to the same levels. In a recent report, LS174T colonic epithelial cells, grown in monolayers, were rarely observed to undergo E. histolytica-mediated trogocytosis. The authors postulated that limited flexibility of the plasma membrane due to junctional complexes in cells grown in monolayers might limit trogocytosis by the parasite [11].

\section{Inflammation and Macrophage Migration Inhibitory Factor Cytokine}

Inflammation is a hallmark of amebic colitis; in fact, colitis literally means inflammation of the colon (Fig. 1). Amebic colitis is characterized by the secretion of pro-inflammatory cytokines and infiltration of the colon by immune cells, which would explain why it is often misdiagnosed as inflammatory bowel disease [2•]. The gut inflammatory response also contributes to the tissue destruction seen in amebic colitis [12]. This notion was best exemplified in a previous study using a mouse model, which showed that persistent inflammation induced the classic flask-shaped ulcer of amebic colitis despite the lack of significant tissue invasion by E. histolytica parasites [13].
Neutrophils are one of the first responders to infiltrate the intestinal tract at the site of inflammation during amebic colitis $[12,14]$. Neutrophils are implicated in both protection and pathology in amebic mouse models $[15,16]$. Neutrophils generate oxygen free radicals that are capable of killing invading parasites, but are also responsible for collateral tissue damage during the inflammatory period, which might explain their protective and destructive role in amebiasis [12]. This is further compounded by the fact that $E$. histolytica parasites have evolved strategies to evade the immune response and persist in the host, further exacerbating the damage caused by the lingering inflammatory response to invading parasites [12].

Intestinal epithelial cells are the first cell types to come into contact with $E$. histolytica (Fig. 2). It has been known for a while that before making cell contact, trophozoites secrete immunomodulatory proteins that stimulate epithelial cells, resulting in cytokine production and subsequent inflammatory cell infiltration $[17,18]$. A variety of cells, including intestinal epithelial cells, produce interleukin-8 (IL-8), a potent neutrophil chemoattractant cytokine. In patients with amebic colitis, higher colonic tissue levels of IL-8 and neutrophils are associated with more severe disease [19-21]. Another cytokine that can result in undesirable effects when produced in excess is TNF- $\alpha$. Higher TNF- $\alpha$ production was shown to correlate with $E$. histolytica diarrhea in children [22]. TNF- $\alpha$ was also shown to mediate the tissue destruction seen in amebic liver abscess in a mouse model [23].

Many parasitic pathogens, including E. histolytica, express a homolog of the pro-inflammatory cytokine macrophage migration inhibitory factor (MIF) [24-28, 29••]. E. histolytica MIF (EhMIF) was recently shown to be a crucial parasite mediator of gut inflammation [29・•]. A positive correlation was found between $E h M I F$ levels and intestinal inflammation in persons with amebic colitis. EhMIF induced chemokine expression, neutrophil influx, and mucosal damage in cellular and mouse models of amebiasis [29••]. Also, EhMIF enhanced TNF- $\alpha$ production by macrophages [25]. Infected children develop antibodies against $E h \mathrm{MIF}$, which correlates with protection from future infection [25, 29••]. These studies suggest that $E h \mathrm{MIF}$ might have a role as an effective immunomodulatory target to prevent or reduce immunopathology in amebiasis.

Inflammasomes are key signaling platforms that detect pathogens and activate the pro-inflammatory cytokines IL$1 \beta$ and IL-18 [30]. The NLRP3 inflammasome is activated by E. histolytica; however, its role in immunopathology and tissue destruction is not yet fully understood [31]. While a recent report found that MIF was required for NLRP3 inflammasome activation [32], the role of EhMIF in NLRP3 inflammasome activation remains unknown.

Nitroimidazoles antibiotics, such as metronidazole, are the mainstay therapy for amebic colitis $[1 \bullet \bullet]$. However, metronidazole alone is sometimes not enough for severe amebic 
colitis and even surgical removal of the inflamed colon may or may not prevent death [2•]. Studies in preclinical mouse models show that while metronidazole is very effective at killing ameba, it had little effect on E. histolytica-induced mucosal inflammation [33, 34]. Blocking parasite mediators of host inflammation such as EhMIF may help to attenuate disease, and these adjunctive anti-inflammatory strategies may lead to the improvement of the clinical outcomes of amebic colitis.

\section{Invasion}

Tissue invasion by E. histolytica plays an important role in the pathogenesis of amebiasis. In clinicopathological studies of patients with severe amebic colitis, lesions extending beyond the cecum and depth of tissue invasion were associated with worse outcomes $[35,36]$.

The extracellular matrix (ECM) is a complex meshwork of proteins that provides support for tissues. The ECM can act as a physical barrier; thus, breakdown of the ECM is often required to promote cell movement through tissue. Matrix metalloproteinases (MMPs) are the main enzymes involved in ECM degradation, with at least 23 human MMPs identified so far [37].

MMPs are overexpressed in all protozoan infections [38]. In the context of amebiasis, MMPs were among the top 5 most overexpressed genes in colonic tissue from patients suffering from intestinal amebiasis, and they were recently shown to be necessary for invasion. In a human colon explant model, inhibition of MMP activity blocked invasion of colonic mucosa by $E$. histolytica $[14,39 \bullet \bullet]$. EhMIF has been found to influence the levels of MMP production. The inflammation induced by $E h \mathrm{MIF}$ resulted in an increase in MMP production [29••]. Therefore, E. histolytica parasites may produce MIF to exploit the host inflammatory response to promote tissue invasion.

\section{Human Gut Microbiome and E. histolytica Infection}

E. histolytica and bacteria have coevolved in the same intestinal environment over evolutionary time. Studies in microbiota-controlled animal models dating back more than half a century ago demonstrated that ulcerative lesions caused by $E$. histolytica were significantly enhanced in the presence of bacteria [40]. The rapid expansion of human microbiome data has created opportunities for further understanding the role of the microbiota in amebiasis.

Recently, several human studies have revealed a significant change in the microbiota of patients with amebiasis. A strong correlation between the presence of E. histolytica and certain bacterial groups of the intestinal microbiota was found in an evaluation of the microbiota composition in rural populations of Cameroon [41]. However, this study had several limitations, including the use of microscopy to detect Entamoeba. Microscopy does not distinguish nonpathogenic E. dispar from E. histolytica, the causative agents of amebiasis [1••]. Higher abundance of Prevotella copri, a species associated with gut inflammation, was found in children with diarrhea due to E. histolytica as compared with those with asymptomatic $E$. histolytica infection in a study conducted in an endemic area of Bangladesh [42••]. Also, a cross-sectional study of patients attending gastroenterology clinics in the Limpopo Province of South Africa found higher levels of $P$. copri in diarrhea due to E. histolytica when compared with nondiarrheal E. histolytica colonization [43]. While these studies did not determine whether $P$. copri changes were the cause or effect of the disease, preliminary data suggest that $P$. copri expansion occurred prior to infection with E. histolytica and symptomatic disease [44].

Prevotella species are anaerobic gram-negative bacteria that constitute a major part of the normal flora of the mouth, gastrointestinal tract, and female genital tract. Interestingly, emerging studies have linked increased Prevotella abundance to inflammatory disorders [45]. Prevotella spp. are capable of inducing IL-8 and IL-6 secretion by epithelial cells, resulting in Th17 responses and neutrophil recruitment in the intestinal mucosa [45]. It is plausible that increased $P$. copri disrupts gut homeostasis and tips the balance toward a pro-inflammatory state which then amplifies $E$. histolyica-induced inflammation, resulting in immunopathology and symptomatic infection. Further studies, however, are needed to confirm this theory.

\section{Genetic Tools for Investigating E. histolytica Pathogenesis}

The molecular processes underlying the pathogenicity of E. histolytica are not fully understood. Therefore, genetic techniques are needed to further understand the pathogenesis of disease caused by E. histolytica. Here, we discuss the developments in the genetic methods applicable to E. histolytica.

Gene silencing has been achieved using a unique strain of E. histolytica called G3, where several amoebapore genes (ap$a, a p-b$, and SAPLIP) were permanently silenced [46]. Using this strain and the regulatory region of the endogenous $a p-a$ gene, several different genes have been successfully silenced [9]. However, this method does not allow for the silencing of a single gene. Gene silencing by exploiting the endogenous RNA interference pathway of eukaryotic cells has also been utilized in E. histolytica [47]. Efficient but variable degrees of 
gene silencing are achieved by this approach. RNA interference methods that have been used successfully include antisense RNA expression [7] and RNAi "trigger"-based gene silencing [48].

In addition to knocking down gene expression, overexpression is often used to study the impact of gain of gene function in an organism. Different vector systems have been successfully used in E. histolytica for constitutive and inducible gene overexpression. For example, using the pKT3M vector, EhMIF gene was constitutively overexpressed in a virulent strain of $E$. histolytica, which was used to study its effect on mucosal inflammation in an amebic colitis mouse model [29.•]. It is important to note that $E h \mathrm{MIF}$ is a soluble secreted and non-toxic protein which enabled successful constitutive overexpression [29•0]. In addition, inducible systems such as pEhHYGB-Tet-0-CAT vector are available for tetracyclineinduced overexpression [49]. Furthermore, studies exploring $E$. histolytica virulent genes have overexpressed a dominant negative mutant protein to inhibit the endogenous protein function [9].

Despite all the current methods available for genetic manipulation, there is a need for developing a complete gene knockout system in E. histolytica. This has been achieved in other protist parasites [50,51]. Efforts are underway to develop CRISPR-Cas9-mediated gene targeting in E. histolytica. So far, successful expression of the guide RNA and a modified version of Cas9 in E. histolytica trophozoites using a single plasmid approach has been achieved.

\section{Conclusion}

E. histolytica infection continues to cause great suffering worldwide. Recent studies have helped to expand our understanding of the pathogenesis of amebiasis. The pathogenesis appears to result from parasite cytotoxic activity, damaging inflammatory response, and invasion. Despite these advances, fundamental questions remain unanswered (Table 2). The answers to these questions may lay the foundation for translating scientific discoveries into clinical interventions.

Table 2 Outstanding questions

Are there host cell factors that promote resistance to trogocytosis?

Would nitroimidazoles antiprotozoal therapy in conjunction with anti-inflammatory strategies by blocking EhMIF activity prove superior to nitroimidazoles alone in reducing tissue damage and symptoms in severe amebiasis?

What is the mechanism by which increased $P$. copri abundance leads to symptomatic E. histolyica infection?

Will CRISPR genetic knockout develop into a reliable technique in E. histolyica?
Acknowledgments We thank William Petri for his helpful advice. We apologize to all the colleagues we were unable to cite due to space limitations.

Funding Information This work was supported by the National Institutes of Health (NIH) R01AI026649-27S1, K08AI119181, and the Robert Wood Johnson Foundation-Harold Amos Medical Faculty Development Program Award.

\section{Compliance with Ethical Standards}

Conflict of Interest The authors declare that they have no conflict of interest.

Human and Animal Rights and Informed Consent This article does not contain any studies with human or animal subjects performed by any of the authors.

Open Access This article is distributed under the terms of the Creative Commons Attribution 4.0 International License (http:// creativecommons.org/licenses/by/4.0/), which permits unrestricted use, distribution, and reproduction in any medium, provided you give appropriate credit to the original author(s) and the source, provide a link to the Creative Commons license, and indicate if changes were made.

Publisher's Note Springer Nature remains neutral with regard to jurisdictional claims in published maps and institutional affiliations.

\section{References}

Papers of particular interest, published recently, have been highlighted as:

- Of importance

•• Of major importance

1.• Shirley DT, Farr L, Watanabe K, Moonah S. A Review of the Global Burden, New Diagnostics, and Current Therapeutics for Amebiasis. Open Forum Infect Dis. 2018;5(7):ofy161). https:// doi.org/10.1093/ofid/ofy161 The authors provide an updated clinical review of the epidemiology, clinical features, diagnosis, and treatment of amebiasis.

2. Shirley D-A, Moonah S. Fulminant amebic colitis after corticosteroid therapy: a systematic review. PLoS Negl Trop Dis. 2016;10(7): e0004879. https://doi.org/10.1371/journal.pntd.0004879 High mortality rate associated with severe colitis despite treatment with metronidazole.

3. Swaminathan A, Torresi J, Schlagenhauf P, Thursky K, WilderSmith A, Connor BA, et al. A global study of pathogens and host risk factors associated with infectious gastrointestinal disease in returned international travellers. J Infect. 2009;59(1):19-27. https://doi.org/10.1016/j.jinf.2009.05.008.

4. Wu N, Freiman JS. Caecal ulceration in an asymptomatic man. Gut. 2017;66(5):886. https://doi.org/10.1136/gutjnl-2016-312811.

5. Huston CD, Houpt ER, Mann BJ, Hahn CS, Petri WA Jr. Caspase 3-dependent killing of host cells by the parasite Entamoeba histolytica. Cell Microbiol. 2000;2(6):617-25.

6. Ralston KS, Petri WA Jr. Tissue destruction and invasion by Entamoeba histolytica. Trends Parasitol. 2011;27(6):254-63.

7. Somlata BS, Bhattacharya A. A C2 domain protein kinase initiates phagocytosis in the protozoan parasite Entamoeba histolytica. Nat 
Commun. 2011;2:230. https://doi.org/10.1038/ncomms1199 https://www.nature.com/articles/ncomms1199\#supplementaryinformation.

8.• Ralston KS, Solga MD, Mackey-Lawrence NM, Bhattacharya A, Petri WA Jr. Trogocytosis by Entamoeba histolytica contributes to cell killing and tissue invasion. Nature. 2014;508(7497):526 First description of trogocytosis in $E$. histolytica.

9. Somlata N-TK, Nozaki T. AGC family kinase 1 participates in trogocytosis but not in phagocytosis in Entamoeba histolytica. Nat Commun. 2017;8(1):101. https://doi.org/10.1038/s41467017-00199-y.

10. Grace E, Asbill S, Virga K. Naegleria fowleri: a review of the pathogenesis, diagnosis, and treatment options. Antimicrobial agents and chemotherapy. 2015:AAC. 01293-15.

11. Cornick S, Moreau F, Gaisano HY, Chadee K. Entamoeba histolytica-induced mucin exocytosis is mediated by VAMP8 and is critical in mucosal innate host defense. MBio. 2017;8(5): e01323-17.

12. Moonah SN, Jiang NM, Petri WA Jr. Host immune response to intestinal amebiasis. PLoS Pathog. 2013;9(8):e1003489. https:// doi.org/10.1371/journal.ppat.1003489.

13. Ghosh PK, Mancilla R, Ortiz-Ortiz L. Intestinal amebiasis: histopathologic features in experimentally infected mice. Arch Med Res. 1994;25(3):297-302.

14. Peterson KM, Guo X, Elkahloun AG, Mondal D, Bardhan PK, Sugawara A, et al. The expression of REG 1A and REG 1B is increased during acute amebic colitis. Parasitol Int. 2011;60(3): 296-300.

15. Seydel KB, Li E, Zhang Z, Stanley SL. Epithelial cell-initiated inflammation plays a crucial role in early tissue damage in amebic infection of human intestine. Gastroenterology. 1998;115(6):144653.

16. Watanabe K, Gilchrist CA, Uddin MJ, Burgess SL, Abhyankar MM, Moonah SN, et al. Microbiome-mediated neutrophil recruitment via CXCR2 and protection from amebic colitis. PLoS Pathog. 2017;13(8):e1006513.

17. $\mathrm{Yu}$ Y, Chadee K. Entamoeba histolytica stimulates interleukin 8 from human colonic epithelial cells without parasite-enterocyte contact. Gastroenterology. 1997;112(5):1536-47.

18. Takeuchi A, Phillips BP. Electron microscope studies of experimental Entamoeba Histolytica infection in the guinea pig: I. Penetration of the intestinal epithelium by trophozoites. Am J Trop Med Hyg. 1975;24(1):34-48

19. Ventura-Juárez J, Barba-Gallardo L, Muñoz-Fernández L, Martínez-Medina L, Márquez-Díaz F, Sosa-Díaz S, et al. Immunohistochemical characterization of human fulminant amoebic colitis. Parasite Immunol. 2007;29(4):201-9.

20. Sierra-Puente R, Campos-Rodríguez R, Jarillo-Luna RA, MuñozFernández L, Rodríguez M, Muñoz-Ortega M, et al. Expression of immune modulator cytokines in human fulminant amoebic colitis. Parasite Immunol. 2009;31(7):384-91.

21. Dickson-Gonzalez SM, de Uribe ML, Rodriguez-Morales AJ. Polymorphonuclear neutrophil infiltration intensity as consequence of Entamoeba histolytica density in amebic colitis. Surg Infect. 2009;10(2):91-7.

22. Peterson KM, Shu J, Duggal P, Haque R, Mondal D, Petri WA Jr. Association between TNF-alpha and Entamoeba histolytica diarrhea. Am J Trop Med Hyg. 2010;82(4):620-5. https://doi.org/10. 4269/ajtmh.2010.09-0493.

23. Helk E, Bernin H, Ernst T, Ittrich H, Jacobs T, Heeren J, et al. TNFalpha-mediated liver destruction by Kupffer cells and Ly6Chi monocytes during Entamoeba histolytica infection. PLoS Pathog. 2013;9(1):e1003096. https://doi.org/10.1371/journal.ppat. 1003096

24. Garcia AB, Siu E, Sun T, Exler V, Brito L, Hekele A, et al. Neutralization of the plasmodium-encoded MIF ortholog confers protective immunity against malaria infection. Nat Commun. 2018;9(1):2714.

25. Moonah SN, Abhyankar MM, Haque R, Petri WA Jr. The macrophage migration inhibitory factor homolog of Entamoeba histolytica binds to and immunomodulates host macrophages. Infect Immun. 2014;82:3523-30. https://doi.org/10.1128/iai. 01812-14.

26. Holowka T, Castilho TM, Garcia AB, Sun T, McMahon-Pratt D, Bucala R. Leishmania-encoded orthologs of macrophage migration inhibitory factor regulate host immunity to promote parasite persistence. FASEB J. 2016;30(6):2249-65. https://doi.org/10.1096/fj. 201500189R.

27. Sun T, Holowka T, Song Y, Zierow S, Leng L, Chen Y, et al. A plasmodium-encoded cytokine suppresses T-cell immunity during malaria. Proc Natl Acad Sci U S A. 2012;109(31):E2117-26. https://doi.org/10.1073/pnas.1206573109.

28. Ghosh S, Leaton LA, Farr L, Barfield A, Moonah S. Interaction between parasite-encoded JAB1/CSN5 and macrophage migration inhibitory factor proteins attenuates its proinflammatory function. Sci Rep. 2018;8:10241.

29.• Ngobeni R, Abhyankar MM, Jiang NM, Farr LA, Samie A, Haque $\mathrm{R}$, et al. Entamoeba histolytica-encoded homolog of macrophage migration inhibitory factor contributes to mucosal inflammation during amebic colitis. J Infect Dis. 2017;215(8):1294-302. https:// doi.org/10.1093/infdis/jix076 Identification of a specific parasiteencoded cytokine, $E$. histolytica migration inhibitory factor (EhMIF), which mediates inflammation during colitis.

30. Latz E, Xiao TS, Stutz A. Activation and regulation of the inflammasomes. Nat Rev Immunol. 2013;13(6):397-411.

31. Mortimer L, Moreau F, Cornick S, Chadee K. The NLRP3 inflammasome is a pathogen sensor for invasive Entamoeba histolytica via activation of $\alpha 5 \beta 1$ integrin at the macrophageamebae intercellular junction. PLoS Pathog. 2015;11(5): e1004887.

32. Lang T, Lee JP, Elgass K, Pinar AA, Tate MD, Aitken EH, et al. Macrophage migration inhibitory factor is required for NLRP3 inflammasome activation. Nat Commun. 2018;9(1):2223.

33. Debnath A, Parsonage D, Andrade RM, He C, Cobo ER, Hirata K, et al. A high-throughput drug screen for Entamoeba histolytica identifies a new lead and target. Nat Med. 2012;18(6):956-60 http://www.nature.com/nm/journal/v18/n6/abs/nm.2758.html\# supplementary-information.

34. Becker S, Hoffman P, Houpt ER. Efficacy of antiamebic drugs in a mouse model. Am J Trop Med Hyg. 2011;84(4):581-6. https://doi. org/10.4269/ajtmh.2011.10-0580.

35. Chaturvedi R, Gupte PA, Joshi AS. Fulminant amoebic colitis: a clinicopathological study of 30 cases. Postgrad Med J. 2015;91(1074):200-5.

36. Takahashi T, Gamboa-Dominguez A, Gomez-Mendez TJ, Remes JM, Rembis V, Martinez-Gonzalez D, et al. Fulminant amebic colitis. Dis Colon Rectum. 1997;40(11):1362-7.

37. Bonnans C, Chou J, Werb Z. Remodelling the extracellular matrix in development and disease. Nat Rev Mol Cell Biol. 2014;15(12): 786-801.

38. Geurts N, Opdenakker G, Van den Steen PE. Matrix metalloproteinases as therapeutic targets in protozoan parasitic infections. Pharmacol Ther. 2012;133(3):257-79. https://doi.org/10.1016/j. pharmthera.2011.11.008.

39.• Thibeaux R, Ave P, Bernier M, Morcelet M, Frileux P, Guillen N, et al. The parasite Entamoeba histolytica exploits the activities of human matrix metalloproteinases to invade colonic tissue. Nat Commun. 2014;5:5142. https://doi.org/10.1038/ncomms6142 Metalloproteinases (MMPs) are necessary for $E$. histolytica tissue invasion. 
40. Phillips BP, Wolfe PA, Rees CW, Gordon HA, Wright WH, Reyniers JA. Studies on the ameba-bacteria relationship in amebiasis. Am J Trop Med Hyg. 1955;4(4):675-92.

41. Morton ER, Lynch J, Froment A, Lafosse S, Heyer E, Przeworski $\mathrm{M}$, et al. Variation in rural African gut microbiota is strongly correlated with colonization by Entamoeba and subsistence. PLoS Genet. 2015;11(11):e1005658. https://doi.org/10.1371/journal. pgen.1005658.

42.• Gilchrist CA, Petri SE, Schneider BN, Reichman DJ, Jiang N, Begum S, et al. Role of the gut microbiota of children in diarrhea due to the protozoan parasite Entamoeba histolytica. J Infect Dis. 2015;213(10):1579-85 Expansion of the Prevotella copri component of the human intestinal microbiome impacts the clinical outcome of $\boldsymbol{E}$. histolytica infection.

43. Ngobeni R, Samie A, Moonah S, Watanabe K, Petri WA Jr, Gilchrist C. Entamoeba species in South Africa: correlations with the host microbiome, parasite burdens, and first description of Entamoeba bangladeshi outside of Asia. J Infect Dis. 2017;216(12):1592-600. https://doi.org/10.1093/infdis/jix535.

44. Gilchrist CA, Schneider BN, Alam M, Donowitz JR, Kabir $\mathrm{M}$, Petri Jr WA et al., editors. Gut microbiome change prior to the onset of amebiasis. American Journal of Tropical Medicine and Hygiene; 2017: AMER SOC TROP MED \&
HYGIENE 8000 WESTPARK DR, STE 130, MCLEAN, VA 22101 USA.

45. Larsen JM. The immune response to Prevotella bacteria in chronic inflammatory disease. Immunology. 2017;151(4):363-74.

46. Bracha R, Nuchamowitz Y, Anbar M, Mirelman D. Transcriptional silencing of multiple genes in trophozoites of Entamoeba histolytica. PLoS Pathog. 2006;2(5):e48.

47. Zhang H, Pompey JM, Singh U. RNA interference in Entamoeba histolytica: implications for parasite biology and gene silencing. Future Microbiol. 2011;6(1):103-17.

48. Morf L, Pearson RJ, Wang AS, Singh U. Robust gene silencing mediated by antisense small RNAs in the pathogenic protist Entamoeba histolytica. Nucleic Acids Res. 2013;41(20):9424-37.

49. Babuta M, Mansuri MS, Bhattacharya S, Bhattacharya A. The Entamoeba histolytica, Arp2/3 complex is recruited to phagocytic cups through an atypical kinase EhAK1. PLoS Pathog. 2015;11(12): e1005310.

50. Vinayak S, Pawlowic MC, Sateriale A, Brooks CF, Studstill CJ, Bar-Peled Y, et al. Genetic modification of the diarrhoeal pathogen Cryptosporidium parvum. Nature. 2015;523(7561):477-80.

51. Lander N, Chiurillo MA, Docampo R. Genome editing by CRISPR/Cas9: a game change in the genetic manipulation of protists. J Eukaryot Microbiol. 2016;63(5):679-90. 